\title{
The Prevalence of Reading Disabilities among Primary Stage Students in the Kingdom of Bahrain
}

\author{
Muneera Ali Hussain Alfadhel \\ Bahrain
}

\begin{abstract}
The aim of this research is to know the prevalence of reading disabilities (RD) among the primary school students in Bahrain and to know the factors that affects the prevalence rates such as, the residential areas (governorates), and the difficulty type (realizing the word or reading comprehension) and gender. The target research population is the $4^{\text {th }}$ primary- school students in Bahrain of the school year 2014-2015. Research population is (1006) Bahraini pupils from Bahraini districts schools. The researcher used the following research tools: Sequential colored matrixes tests (by: Ravin, the Arabization of Qurashy, 1978), and achievement test for the fourth-grade students (prepared by the researcher). As well as (recognizing the word) test done (by the researcher), and the scale of diagnostic appreciation of (RD) (prepared by: Alziat, 2007). After making the suitable statistical tools to answer the research questions, the researcher found the following results: 1-The percentage of (RD) in Bahrain for the fourth-grade students reached about (\%10.47). 2-There are significant statistical differences in the rates of the prevailing of (RD) for the fourth-grade students in Bahrain according to the difficulty type. 3-There are significant statistical differences in the rates of the prevailing of $(R D)$ for the fourth-grade students in Bahrain according to the gender differences towards males. 4-There aren't significant statistical differences in the rates of the prevailing of $(R D)$ for the fourth-grade students in Bahrain because of the different school districts.
\end{abstract}

\section{Introduction}

The field of learning disabilities is one of the most complex areas of education in general, given the nature and size of the phenomenon. According to the American Bureau of Education, the prevalence rate (51.1\% of the total number of people enrolled in the special education program) is at the international and Arab level (Abu Nyan, 2001) The results of some surveys show that the percentage educational systems have increased at a high rate within the regular school, such as Al-Enezi [8], which aims to find the prevalence of learning disabilities among elementary and middle school students in Kuwait.

Reading is one of the main axes of academic learning disabilities, if not the main and most important one. Many researchers consider it to be the main cause of school failure. It affects self-esteem and self-efficacy [5].
Researchers also found that reading disabilities represent the most common types of academic learning disabilities, and that $80 \%$ of students with learning disabilities have reading disabilities [5]. Rahim [3] refers to the concept of learning disabilities as a partial inability to read, to understand what a student is reading, to be sustained, not to result from low mental capacity, hearing or visual impairment, or emotional disorders, or disorders resulting from poor social conditions. "

Many researchers have tried to decide the prevalence of learning disabilities and found them to vary by demographic variables such as gender, age, and socioeconomic level [6]. This research is considered one of the foundations that can give an indication to those concerned and to those involved in this field of realizing the problem about the extent of the disabilities of learning to read in elementary school students. To cut this problem that threatens the future of our children, And the preparation and financing of educational programs. This research is considered one of the foundations that can give an indication to those concerned and to those involved in this field of realizing the problem about the extent of the disabilities of learning to read in elementary school students. To cut this problem that threatens the future of our children, And the preparation and financing of educational programs.

In the light of the lack of the Kingdom of Bahrain to check the survey of the prevalence of learning disabilities on the one hand, and the prevalence of the prevalence of learning disabilities with some taxonomic variables. (type, type of difficulty, and residential area), however, this research came to know the prevalence of learning disabilities in the Kingdom of Bahrain in the light of some taxonomic variables.

\section{Research Methodology}

This research was adopted in its application to the descriptive approach, as it works to study the phenomenon as it is in reality

Without interference, and this is consistent with the current research aims.

\subsection{The research samples}

Approximately (10\%) of the research population was enrolled in the fourth grade of primary school, reaching (1006) students. This is the total number of the sample represented by the research community 
(457 males and 549 females) from (20) schools in all governorates of the Kingdom of Bahrain. The sample was selected according to the randomized cluster method.

\subsection{Search tools}

The following tools were used in the search:

- The test of the successive color matrices of Raven, the Arabization of al-Qurashi [1].

- A measure of the behavioral characteristics of learning disabilities [4].

- Achievement in reading for the fourth grade of primary (researcher's preparation, 2016).

- Achievement test in defining the word for the fourth grade of primary (researcher's preparation, 2016).

- Raven's successive color matrix matrices [1]:

This test is one of the most common nonverbal intelligence measures used to measure general mental capacity. The correlation between the colored matrices was calculated. The results showed that there was a positive correlation at 0.35 . The validity of the test was calculated using the methods of predictive honesty and formality. The test proved to be highly reliable (0.79) and the half-split method between the test halves using the Gitman equation. The stability coefficient (0.82) in the second application, and the internal consistency method, between the sub-sections of the test, Statistically at the level of (0.01).

- A measure of the behavioral characteristics of learning disabilities [4]:

The validity of the content was calculated as the correlation coefficients of each paragraph were used in the total scores of the learning disabilities scale. The correlation coefficients of the reading disabilities index ranged from (0.62 -0.767), indicating the consistency of paragraphs Measurement of reading disabilities as measured by.

The correlation between the reading disabilities and measures of academic and developmental disabilities was calculated. The results showed strong correlation and statistical function between the coefficients. The stability of diagnostic measures was calculated between (0.941-0.982), and stability coefficients were obtained in the midterm split, ranging from $(0.922$ to 0.976$)$.

- Achievement test in reading for the fourth grade of primary (researcher's preparation, 2016):

The test aims to measure the level of reading among fourth graders.

- $\quad$ Psychometric properties of the test

- Sincerity test:

$\checkmark$ Content certified
In order to verify the validity of the test, the test was presented to a group of specialists in the field of Arabic language. The percentage of agreement between the arbitrators on the reading test ranged from $(70 \%$ to $100 \%)$.

$\checkmark$ Stability Test:

To verify the stability of the test, the internal consistency method used for the consistency of the vocabulary was used in the Alpha Cronbach and the Guttman Split-half, and the stability was in alpha Cronbach (0.846), and the stability in the half-way (0.835).

- Achievement test in word recognition for the fourth grade of primary (researcher's preparation, 2016):

- The aim of the test is to diagnose the difficulty of reading the word in reading in the fourth-grade pupils.

- The validity of the test has been calculated

- Believe the content

The test was presented to (5) specialists and experts in the field, and took their opinions on the test, and ranged between $(80 \%-100 \%)$. The test was modified in the light of the opinions of the arbitrators, indicating that the test has an acceptable degree of honesty.

Stability of the test:

To verify the stability of the test, the internal consistency method was used for the stability of the vocabulary in the Alpha Cronbach and the Guttman Split-half, and the stability was in alpha Cronbach (0.607), and the homogeneity was (0.797).

\section{Measures}

\subsection{Sample Sorting Steps}

The spacing test is applied by:

1. The successive matrix matrices (Rafin, Arabization by Alqarashi, 1978) were applied to all the primary sample of the research. The average IQ of the first sample was extracted in the mentioned test, which is in the 50th percentile.

2. The experimental test was performed in the reading (researcher, 2016) on the primary sample after the pilot experiment to verify the psychometric characteristics of the test. The average performance of the first sample was extracted in the mentioned test. The average score was 15.06 with a standard deviation of (4.61).

3. Students whose IQs were intermediate or above and their scores in the intermediate reading test were identified (with one standard deviation). In this light, the number of pupils to whom the spacing test applied was (178).

4. The exclusion criterion was applied to (178) by examining the school records of each student in order to exclude all types of disability, severe 
emotional disorders or environmental conditions, and (18) were excluded from the test students.

5. The diagnostic assessment scale was applied in reading [4] to (160) students, to exclude those with a total of (52) students, thus the last sample number (108).

6. The word identification test (researcher's preparation, 2016). was applied to the last sample of the reading disabilities of (108) students. It was found that (69) students with learning disabilities identified the word $(72.6 \%)$ of the last sample $(27.4 \%)$ of the last sample. The number of absentee students during the course of the test was (13) students in the last sample.

\section{Statistical Methods}

The statistical data were analyzed using the statistical package program (SPSS). To confirm the statistical properties of the test, statistical methods were used: Alpha Cronbach and split-half, as well as the arithmetic mean and standard deviations. To answer the research questions, frequencies and percentages were used, and the Chi-Square test was used.

\section{Results}

In order to answer the first question, the frequency and percentage of pupils with reading disabilities in the light of the first sample (1006) were calculated as shown in Table 1.

Question 1: "What is the prevalence of learning disabilities among primary school students in the Kingdom of Bahrain?"

Table 1. Learning disabilities among primary school students in the Kingdom of Bahrain

\begin{tabular}{llrrr}
\hline \multirow{4}{*}{ Total } & $\begin{array}{l}\text { Number of } \\
\text { Students } \\
\text { Reading } \\
\text { Disabilities }\end{array}$ & Percentage & Value & $\begin{array}{l}\text { Level of } \\
\text { significance }\end{array}$ \\
\hline 1006 & 108 & $\% 10.47$ & 620.38 & 0.000 \\
\hline
\end{tabular}

The results of Table 1 show that the number of pupils with learning disabilities reached (108) students and $(10.47 \%)$. The results of the Kay square test showed that the ratio was statistically significant, with a mean value of less than (0.05).

The results of Table 2 show that the number of students with reading comprehension disabilities reached (26) students and $(27.4 \%)$, while the number of students with disabilities with the word was (69) students and $(72.6 \%)$. The results of the Kay square test showed that the difference between the two ratios was statistically significant, with the value of the observed significance level (0.000), which was below the predefined significance level (0.05), indicating that the prevalence of learning disabilities varies according to the difficulty pattern.

Question 2: "Are the prevalence of learning disabilities in primary school students different from the difficulty pattern (word recognition, reading comprehension) in the Kingdom of Bahrain?"

Table 2. Difficulty patterns

\begin{tabular}{ccccc}
\hline $\begin{array}{c}\text { Style of } \\
\text { difficulty }\end{array}$ & $\begin{array}{c}\text { Num } \\
\text { ber }\end{array}$ & $\begin{array}{c}\text { Percent } \\
\text { age }\end{array}$ & $\begin{array}{c}\text { Value } \\
\chi^{2}\end{array}$ & $\begin{array}{c}\text { Level of } \\
\text { significan } \\
\text { ce }\end{array}$ \\
\hline $\begin{array}{c}\text { Reading } \\
\text { compreh } \\
\text { ension }\end{array}$ & 26 & $\% 27.4$ & & \\
\cline { 1 - 2 } $\begin{array}{c}\text { word } \\
\text { recogniti } \\
\text { on }\end{array}$ & 69 & $\% 72.6$ & & \\
\hline Total & 95 & $\% 100$ & & \\
\hline
\end{tabular}

Question 3: "Do the prevalence of learning disabilities among primary school students vary by gender (male, female) in the Kingdom of Bahrain?"

The results of Table 3 show that the number of males with reading disabilities reached (72) students, in the rate of $(66.7 \%)$, while the number of females with reading disabilities was (36) students, in the rate of $(33.3 \%)$. The Kay test showed that the difference between the two ratios was statistically significant, with the value of the observed significance level (0.001), which was less than the predefined significance level (0.05), indicating that the prevalence of learning disabilities among male primary school students was higher (see Figure 1).

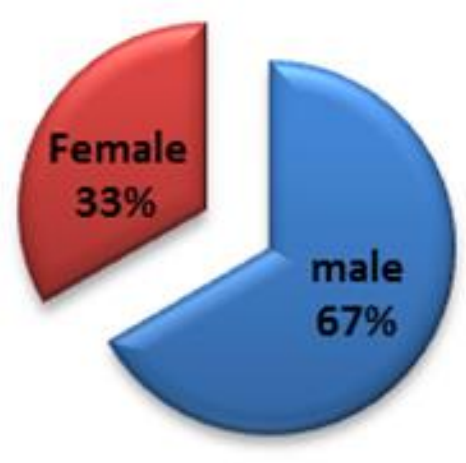

Figure 1. Percentage of male and female with learning disabilities 
Table 3. Variance of learning disabilities by gender

\begin{tabular}{ccccc}
\hline Gender & Number & Percentage & $\begin{array}{c}\text { Value } \\
\chi^{2}\end{array}$ & $\begin{array}{c}\text { Level of } \\
\text { significance }\end{array}$ \\
\hline male & 72 & $\% 66.7$ & & \\
\cline { 1 - 2 } female & 36 & $\% 33.3$ & & 0.001 \\
\cline { 1 - 2 } Total & 108 & $\% 100$ & & \\
\hline
\end{tabular}

Question 4: "Are the prevalence of learning disabilities among primary school students different from the residential area in the Kingdom of Bahrain?"

Table 4. Learning disabilities among primary school students based on the residential area

\begin{tabular}{|c|c|c|c|c|}
\hline $\begin{array}{l}\text { Residential } \\
\text { areas }\end{array}$ & Number & Percentage & $\begin{array}{c}\text { Value } \\
\chi^{2}\end{array}$ & $\begin{array}{c}\text { Level of } \\
\text { significance }\end{array}$ \\
\hline South & 29 & $\% 26.9$ & \multirow{5}{*}{3.48} & \multirow{5}{*}{0.323} \\
\hline North & 34 & $\% 31.4$ & & \\
\hline Capital & 23 & $\% 21.3$ & & \\
\hline Muharraq & 22 & $\% 20.4$ & & \\
\hline Total & 108 & $\% 100$ & & \\
\hline
\end{tabular}

The results of Table 4 show that the percentage of pupils with reading disabilities in the southern region is $(26.9 \%)$, while the percentage of pupils with reading disabilities in the Northern Region is $31.4 \%$,

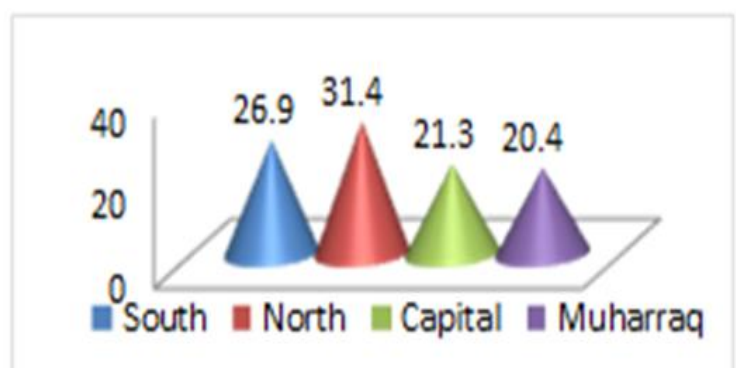

Figure 2. Percentage of pupils with reading disabilities in four regions

The percentage in the capital governorate $(21.3 \%)$, while the percentage in Muharraq Governorate $(20.4 \%)$, the results of the Kay square test showed that the differences between the percentages were not statistically significant, with the value of the observed significance level $(0.323)$ which is greater than the predefined significance level (0.05), indicating that there is no prevalence of reading disabilities varies by region (see Figure 2).

\section{Discussion of Results}

The prevalence of reading disabilities among primary school pupils $(10.47 \%)$ was due to several reasons, including:

1. Despite the existence of the learning disabilities program in all primary schools in the Kingdom of Bahrain, the diagnostic and treatment mechanism for people with learning disabilities is based on the academic aspect only, without paying attention to the developmental aspect.

2. Lack of awareness and knowledge in general, both at the school level, or parents with the characteristics of students with learning disabilities, and how to deal with them.

3. The weak relationship between the school and the family, the family and school relationship have a significant impact on the academic and social skills of students, as they greatly affect academic achievement [9].

4. low social, economic and cultural level of the family, which affects the lack of enough educational stimuli for the student.

The current research results in a difference in the prevalence of learning disabilities according to the type of difficulty. This result can be explained in light of the following:

1. The word is the primary part of the reading process. It includes many of the language skills and phenomena necessary to convert the symbols into spoken words. Thus, the entire reading process depends mainly on these skills. Failure to do so results in failure in the second part of reading. Reading comprehension, if the normal student has difficulty in learning some of these linguistic phenomena, so what are we with disabilities learning to read?!

2. The majority of Arabic language teachers still believe that reading is one skill, while the knowledge of the word and reading comprehension consists of several skills that need several strategies to master them. There are no specific strategies, methods, or programs to teach reading Word and reading comprehension suits those with learning disabilities. 3 . The diagnostic process is not based on what should be. The proper diagnosis is the basic basis for determining the current situation of the student in terms of difficulty and degree, and then the development of the proper treatment plan. Feasibility.

4. The therapeutic activities also lack the scientific foundations on which they should be based. Therefore, most of the activities provided to pupils do not exceed the limits of the teacher's personal judgment, and therefore give them to all students on the various reasons behind the difficulty. 
5. lack of the normal teacher to do his role represented in the intervention before referring students to the teacher of special education, which leads to increase the burden and burden on the teacher of special education, thus shortening the performance of his work to the fullest, and this prevents the performance of effective educational practices, whether that at the level of identification, detection, diagnosis, treatment or follow-up, as we aspire to.

It was found in this research that the prevalence of learning disabilities among males is higher than that of females. This result can be explained in light of the following:

1. Due to biological factors, males may be more prone to learning disabilities due to late maturation. Females and neural growth in females at birth are estimated to be faster than those of males, with a duration of between (3-6) weeks, this difference in maturity is about two years at puberty [7].

2 . It is estimated that the number of male students with learning disabilities exceeds the number of female students with learning disabilities, about two to three times, and the reasons for this difference has nothing to do with mental abilities, but may be due to medical factors, increasing the weight of male birth more than Females are more likely to have difficulty in childbirth. In addition, the nature of male activities is more violent than females, and recurrence may result in malfunction. Male hormone may have a relationship, and there are factors related to maturity, since females mature before males.

1. The results of research on cerebral insemination of information in males and females, it shows that females have a higher specialization in the left brain (verbal tasks) compared to the right brain (visual spatial functions), thus preferring to read, and verbal tasks on mathematics.

2. Socialization plays a prominent role in showing these differences between the sexes, the nature of females tends to sit at home, which gives them more opportunity to study, and the performance of school duties to the fullest, and take the issue of study seriously and attention, unlike the socialization of males, most of his time is spent abroad, and he does not take things seriously, which in turn increases the chances of females exceeding males in school, regardless of their intelligence.

The current research indicates that the prevalence of learning disabilities is not different in the residential area due to several reasons, including the following:

1. The characteristics of the Bahraini society in terms of population census, limited geographical area, customs and traditions, methods of socialization, and the interaction between the components of Bahraini society. These factors contributed to the absence of differences between the four governorates as a homogeneous society. Especially considering the exclusion of non-Arabic-speaking cases from the research sample to neutralize the language factor in influencing the search results and their credibility.

2. This can be explained in light of the fair distribution of educational services by the governorates of the Kingdom of Bahrain in terms of the number of schools, teachers, supervisors, followup and support services. This has contributed fairly to these services in these governorates. There are no differences in the prevalence of reading disabilities among them.

\section{Conclusion}

Learning disabilities are disabilities that affect different areas of life, and a person's lifespan. However, with real support and early intervention, children with learning disabilities can continue to live successfully and distinctly. In order to get real figures, this research has come to represent the problem in the form of numbers; so that specialists can find the right solutions and proper treatment programs, to cut the problem and the risk of aggravation in the future.

\section{References}

[1] A.F.Al-Qurashi, Test the color sequences of the Raven, Dar Al Qalam, Kuwait, 1987.

[2] A.Nayan, I.B.Saad, Learning disabilities Teaching methods and cognitive strategies, Academy of Special Education, Riyadh, 2001.

[3] F.A.Rahim, The psychology of exceptional children and special education strategies, Dar Al-Qalam for Publishing and Distribution, Kuwait,1999.

[4] F.M.Zayat, Manual battery diagnostic measures for learning disabilities. Cognitive Psychology Series, Publishing House for Universities, Cairo, 2007.

[5] F.Zayat, Learning disabilities the theoretical, diagnostic and therapeutic bases. Series of Cognitive Psychology Publishing House for Universities, P4, Cairo, 1998.

[6] N. A. Badian "Reading disability defined as a discrepancy between listening and reading comprehension: A longitudinal study of stability، gender differences، and prevalence," Journal of Learning Disabilities,1999, P 32, 138-148.

[7] R. Waqfi, Theoretical and applied learning disabilities, Dar Al Masirah for Printing, Publishing and Distribution, Amman, 2009.

[8] S. Alenezi, The prevalence of reading disabilities and their relation to some taxonomic variables among primary and middle school students in Kuwait. Unpublished MA, Gulf Arab University, Kingdom of Bahrain, 2011.

[9] S. Goldstein, S.N. Mather, H. Brookes. Learning disabilities challenging behave-ours: a guide to intervention and classroom management, 2001. 